\section{SHREW IN A BEEHIVE}

by S. E. Bland, Regina

The waxen store-house of the honeybee attracts a variety of plunderers. Many of the invaders of weakened colonies or of deserted combs are other insects. Larder beetles, moths, and even tiny mites attempt to feed and reproduce on the pollen which the bees have gathered and stored in the cells of the comb. Pollen, which the bees gather in large quantities, forms the protein portion of the bees' diet.

Other invaders of honeybee domiciles are mammals. These plunderers range from the headstrong bear and cunning man to smaller mammals such as the skunk and mouse. When mammals are the invaders it may be either the honey or the bees themselves that are the attraction. Beekeepers report that bears frequently show a preference for young bee larvae cradled in their cells in the lower portion of the hive, rather than the store of honey in the upper chambers of the hive. This prompts the bear to knock over the hive to get to the lower brood area. Beekeepers in our northern areas keep a rifle loaded for bear, and often a bearskin rug graces their living room. The nocturnal skunk, being unable to upset a beehive, is content to scratch at the hive entrance and then devour the defending bees when they attempt to sting through his long, coarse hair. The threat of the bees' stings seems to do little to deter either the bear or the skunk.

Mice often show an interest in beehives. When fall dictates a winter home, they invade the lower combs beneath a wintering cluster of bees, where they store a collection of seeds for winter sustenance. The winter diet, however, is supplemented with pollen and honey. With the return of spring the bee cluster becomes more active and the mouse must vacate the premises or his lifeless, propolisembalmed carcass will be found on the hive bottom-board by the beekeeper, the bees' stings having served their function. It is quite ordinary practice to board up a hive for the winter, in order to keep mice from entering, but enough space is left for a doorway for the bees.

The smallest mammal found invading beehives is the tiny shrew. Several seasons ago I found the skeletonized remains of one of these small creatures in the spring in a wintered hive. On October 22nd of this year, while inspecting bee equipment for disease in the Birch Hills area, I found a live shrew in a beehive. There were signs that it had been removing dead bees from the comb and devouring them. This section of hive had been gassed earlier because it contained insect pests, so a number of dead bees still remained where they had been trapped within open cells. The fact that this unit had been placed on the grass may have made it somewhat easier for the shrew to enter. Later the shrew was identified as a Masked (or Common) Shrew (Sorex cinereus) by W. Harvey Beck.

Knowing my nature-loving son would be interested in seeing the shrew, I placed it in an empty can with the remnants of a mouse nest and six chilled, half-dead bees. I felt that some food must be provided since I had read about the voracious appetite of this mammal, and bees were the only insect life readily available at the time. In the morning I surprised the butcher in Birch Hills by requesting a mere five cents worth of hamburger. Hawever, in the meantime the shrew had died in its prison; I assumed either from starvation or from a sting from one of the bees which I had offered it, but Mr. Beck tells me that there was no sign of a sting, and suggests that the shrew simply died from nervous exhaustion brought about by handling. These minute mammals, the smallest in the world, are almost constantly active. Their extremely high metabolism requires them to search endlessly for sources of food. 